\title{
Erratum to: Improved Initiation Technique for the Metal Fixed Points
}

\author{
D. R. White - R. S. Mason
}

Published online: 20 November 2010

(C) Springer Science+Business Media, LLC 2010

\section{Erratum to: Int J Thermophys DOI 10.1007/s10765-010-0851-4}

Equation 4 of the original article published online has an error, the denominator and numerator are reversed in the equation. Corrected version is given below:

$$
P e=\frac{V r}{2 \alpha}
$$

The online version of the original article can be found under doi:10.1007/s10765-010-0851-4. 